\title{
The Impact of Hospital Teaching Status on Colonoscopy Perforation Risk: A National Inpatient Sample Study
}

\author{
Mowyad Khalid ${ }^{\mathrm{a}, \mathrm{f}}$, Mazin Khalid ${ }^{\mathrm{b}}$, Vijay Gayam ${ }^{\mathrm{b}}$, Ahmed Yeddi ${ }^{\mathrm{a}}$, Omeralfaroug Adamª \\ Sandipan Chakraborty ${ }^{\mathrm{b}}$, Mohamed Abdallah ${ }^{\mathrm{c}}$, Ahmad Abu-Heija ${ }^{\mathrm{a}}$, Zaid Kalotia, \\ Osama Mukhtar ${ }^{\mathrm{b}}$, Hammam Shereef ${ }^{\mathrm{d}}$, Stephanie Judd
}

\begin{abstract}
Background: Colonoscopy has been widely used as a diagnostic tool for many conditions, including inflammatory bowel disease and colorectal cancer. Colonoscopy complications include perforation, hemorrhage, abdominal pain, as well as anesthesia risk. Although rare, perforation is the most dangerous complication that occurs in the immediate post-colonoscopy period with an estimated risk of less than $0.1 \%$. Studies on colonoscopy perforation risk between teaching hospitals and non-teaching hospitals are scarce.
\end{abstract}

Methods: The National Inpatient Sample database was queried for patients who underwent inpatient colonoscopy between January 2010 and December 2014 in teaching versus non-teaching facilities in order to study their perforation rates. Our study population included 257,006 patients. Univariate regression was performed, and the positive results were analyzed using a multivariate regression module.

Results: Teaching hospitals had a higher risk of perforation (odds ratio 1.23 , confidence interval $1.07-1.42, \mathrm{P}=0.004$ ). Perforation rates were higher in females, patients with inflammatory bowel disease and dilatation of strictures. Polypectomy did not yield any statistical difference between the study groups. Other factors such as AfricanAmerican ethnicity appeared to have a lower risk.

Conclusion: Perforation rates are higher in teaching hospitals. More studies are needed to examine the difference and how to mitigate the risks.

Manuscript submitted November 1, 2019, accepted December 6, 2019

aDepartment of Internal Medicine, Wayne State University/Detroit Medical Center, Detroit, MI, USA

bepartment of Internal Medicine, Interfaith Medical Center, Brooklyn, NY, USA

'Department of Internal Medicine, University of South Dakota, Sioux Falls, SD, USA

dDepartment of Internal Medicine, Beaumont Hospital, Dearborn, MI, USA

eDepartment of Gastroenterology, Wayne State University/John D. Dingell VA Medical Center, Detroit, Michigan, USA

fCorresponding Author: Mowyad Khalid, Department of Internal Medicine, Wayne State University School of Medicine/Detroit Medical Center, $4201 \mathrm{St}$ Antoine St, Detroit, MI 48201, USA. Email: Mowyad_khalid@yahoo.com

doi: https://doi.org/10.14740/gr1234
Keywords: Hospital teaching status; Colonoscopy; Perforation

\section{Introduction}

Since the introduction of colonoscopy in the 1960s [1], it has been widely used as a diagnostic and therapeutic tool for many conditions, including colorectal cancer and polyps, respectively. Colonoscopy complications include perforation, hemorrhage, abdominal pain and the risk of anesthesia. Although rare, perforation is the most dangerous complication that occurs in the immediate post-colonoscopy period with an estimated risk of less than $0.1 \%$ [2].

The quality indicator targets per the American College of Gastroenterology/American Society for Gastrointestinal Endoscopy Task Force on Quality in Endoscopy recommend a target of perforation rate of less than 1 per 500 colonoscopies (less than 1 per thousand screening colonoscopies) [3].

Teaching hospitals are an integral part of the healthcare system. They serve the uninsured population, provide advanced research and specialized patient care, and educate future physicians $[4,5]$. They offer superior care compared to non-teaching hospitals [6]. But, the cost has shown to be higher [7].

Studies examining the risk of colonoscopy perforation in teaching hospitals compared to non-teaching hospitals are lagging. The purpose of our study was to examine the perforation rates among patients undergoing colonoscopy at teaching versus non-teaching hospitals.

\section{Materials and Methods}

\section{Data source}

The National Inpatient Sample (NIS) was utilized, which is a part of the Healthcare Cost and Utilization Project, sponsored by the Agency for Healthcare Research and Quality. The NIS is the most extensive, publicly available inpatient healthcare database. It contains all-payer data from $20 \%$ nonfederal US acute care hospitals. It encompasses more than 7 million unweighted discharges per year. Each hospitalization can be transformed into weighted count by discharge weight provided 
in the dataset to yield national estimates. The data include discharge-level records on demographics, diagnosis, procedures, healthcare statistics, length of stay and utilization data. The database provides hospitalization characteristics in a manner of location and type which divides the hospitals into teaching and non-teaching. The NIS uses the International Classification of Diseases, Ninth Revision, Clinical Modification (ICD-9-CM) coding system to collect 25 discharge diagnoses and 15 procedures on each hospitalization [8].

Since no personal identifiers were used in the registry data, the NIS database is exempt from IRB. Due to the retrospective nature of this study, formal consent is not required.

\section{Study population}

A retrospective analysis of NIS discharge data from January 1, 2010 to December 31, 2014 was performed. ICD-9-CM procedure codes $45.22,45.23,45.25,45.26,45.27$ and 45.43 were used to identify adult patients ( $>18$ years old) who underwent inpatient colonoscopy. We excluded patients with colon cancer using ICD-9-CM diagnosis codes 153.0-154.3, 154.8. Postprocedure perforation was identified using ICD-9-CM diagnosis code for perforation of the intestine and accidental puncture or laceration during a procedure (ICD-9 codes 569.83 and 998.2). Colonoscopies done in urban teaching hospitals were compared to colonoscopies done in rural and non-teaching urban hospitals. Those codes have been validated and used in previous studies $[9,10]$.

\section{Study variables}

The analysis included baseline characteristics of our study cohort, including age, sex, race and insurance type. We included ulcerative colitis (ICD-9-CM diagnosis codes 556.0, 556.1, $556.2,556.3,556.4,556.5,556.6,556.8,556.9)$ and Crohn's disease (ICD-9-CM diagnosis codes CD 555.0, 555.1, 555.2, 555.9 ) to account for inflammatory bowel disease (IBD) as a possible confounder of the primary outcome of post-operative perforation [9]. We also studied the dilatation of stricture and polypectomy rates in both cohorts. We utilized the Elixhauser comorbidity index as a method of categorizing comorbidities of patients based on the International Classification of Diseases (ICD) diagnosis codes.

\section{Outcomes}

The primary outcome of this study was the rate of post-colonoscopy perforation.

\section{Statistical analysis}

We analyzed the data using STATA 15 (StataCorp, College Station, TX, USA). Statistical hypotheses were tested using $\mathrm{P}<$ 0.05 as the level of statistical significance for univariate and multivariate analyses. We used Pearson's Chi-square test for categorical variables and Student's $t$-test for continuous variables. The categorical and continuous variables were stated in percentages and mean \pm standard deviation (SD), correspondingly. A bivariate analysis was conducted to compare the demographics, covariates and outcomes of interest between the study and control groups. The discharge weights were used to estimate $95 \%$ confidence intervals (CIs) for point estimates and reflect nationwide data during the study period (2010 - 2014).

We conducted a multiple logistic regression model to adjust for the covariate variables that were found to be statistically significant in univariate analysis.

\section{Results}

The study population included 257,006 patients from the NIS registry who underwent inpatient colonoscopy from 2010 to 2014. When discharge weights were applied, the study population represents $1,273,042$ discharged patients for the study period. Non-teaching hospitals had more patients $(669,250)$ when compared to teaching hospitals $(603,792)$. The teaching hospitals had a mean age of 66 years, with females representing $53 \%$ of the services population, while non-teaching facilities had a mean age of 68 years with more female patients $(55 \%)$. The racial distribution between the teaching and nonteaching facilities included whites $(62 \%$ vs. $72 \%, \mathrm{P}<0.0001)$, African-Americans (23\% vs. 14\%, P < 0.0001), Hispanics and Asians, which were similar between two groups $(\mathrm{P}<0.0001)$. Teaching hospitals cared for a significantly higher number of patients with ulcerative colitis and Crohn's disease $(9 \%$ and $1.6 \%$, respectively $\mathrm{P}<0.0001)$. Polypectomy rates were statistically similar between the two cohorts $(P=0.17)$, in contrast with the dilatation of stricture rates, which were higher in teaching facilities $(\mathrm{P}=0.002)$. Patients of teaching facilities had more comorbidities, with $70 \%$ of the cohort having Elixhauser score of 4 or more when compared to $67 \%$ in the comparison cohort $(\mathrm{P}<0.0001)$ (Table 1).

The univariate analysis results are shown in Table 2, and statistically significant data were used in the multiple logistic regression. After adjustment with multivariate regression (Table 3), the teaching facilities had a higher odds ratio (OR) of perforation 1.23 (CI $1.07-1.42, \mathrm{P}=0.004)$. There was statistical significance between the two groups when it came to female sex (OR 1.35, 1.16 - 1.56, P $\leq 0.001)$, ulcerative colitis and Crohn's disease (OR 2.41 and 2.40, respectively with $\mathrm{P} \leq$ $0.001)$. The highest OR $(5.19, \mathrm{P} \leq 0.001)$ was observed in patients undergoing dilatation of a stricture as can be anticipated. Interestingly, polypectomy did not affect the rate of perforation. We noted that African-Americans and races labeled as others were less likely to develop perforation following colonoscopy when compared to the white population. Comorbidities were not noted to affect the OR for perforation.

\section{Discussion}

In our nationally representative study, we found a statistically 
Table 1. Demographic Characteristics of Patients Who Underwent Colonoscopy Between 2010 and 2014 Stratified by Teaching vs. Non-Teaching Facilities

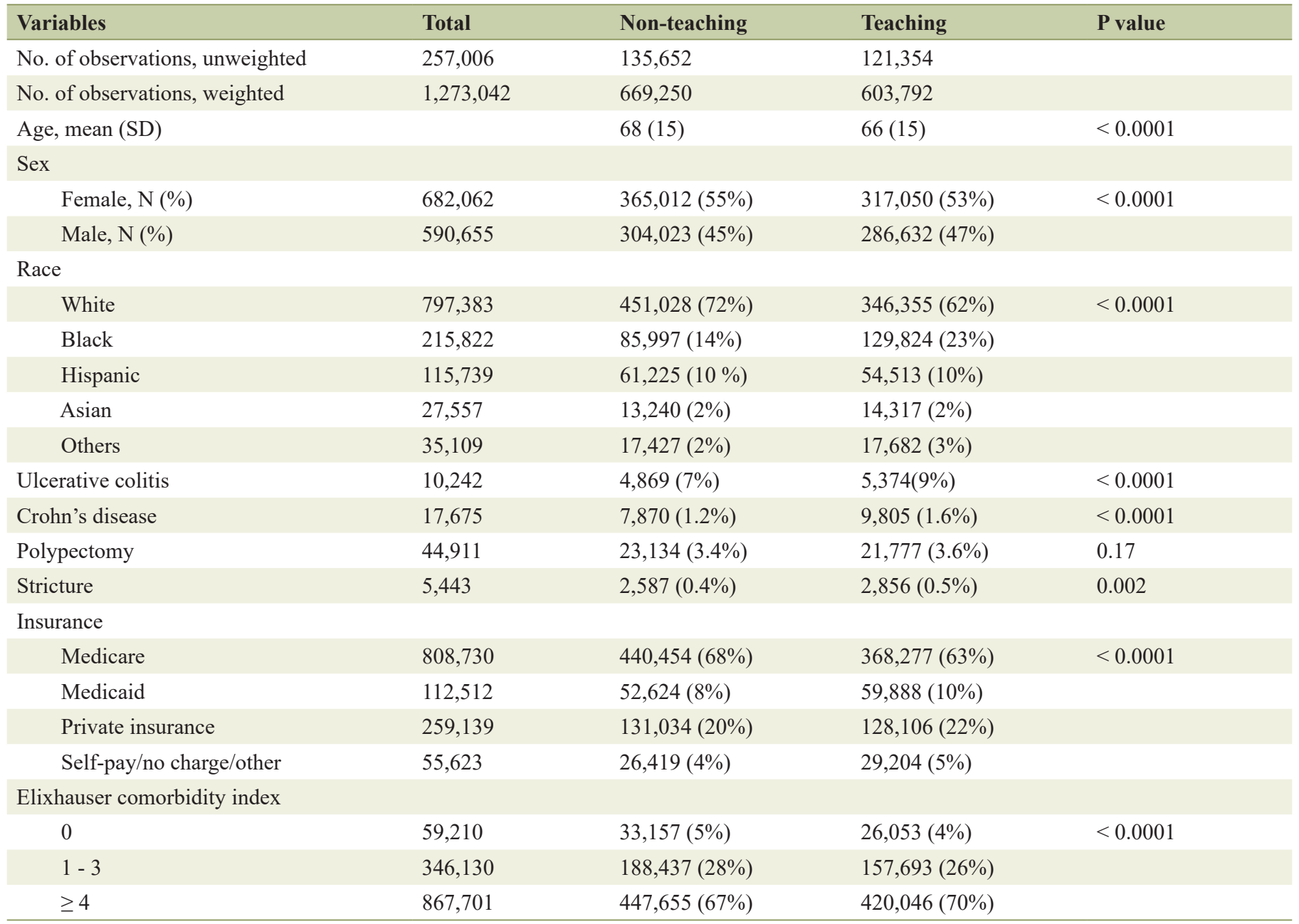

SD: standard deviation.

significant increase in the risk of colonoscopic perforation in teaching hospitals compared to non-teaching. After multivariate regression analysis, factors associated with increased risk of perforation included female gender, IBD and dilation of a stricture. Becoming aware of patients at increased risk for complications is essential, considering the increasing number of colonoscopy procedures [11].

A possible explanation for the increase in perforation is that teaching hospitals treat referred patients with complex conditions [12]. Multiple studies demonstrated that referred patients, including intensive care unit patients, have higher rates of complications, mortality and length of stay [13-15].

Studies examining the effect of fellows' involvement on colonoscopy outcomes are contradicting. Smaller studies, including a Swedish study of about 6,000 colonoscopies, and another study of about 1,000 patients all reported increased perforation risk with less experience $[16,17]$. On the other hand, larger studies, including Wexner et al of about 13,000 colonoscopies and an Australian study of 23,000 patients, found no statistical significance $[18,19]$. Anderson et al reported a non-statistically significant increased risk of perforation $(\mathrm{P}=$ 0.625 ) when gastroenterology fellows are involved [20]. However, adverse colonoscopy events were reported to be associated with lesser experience [21, 22]. Marshal et al suggested that colonoscopy skills are acquired with time, needing more than 100 procedures to reach competence, which is higher than the number needed for graduation [23].

Previous studies indicated an increased risk of perforation with colonoscopic intervention compared to screening [22, 24]. Proposed mechanisms include trauma from the scope and air insufflation, endoscopic submucosal dissection of colorectal tumors [25], removal of polyps greater the $2 \mathrm{~cm}$ [26] and colon stricture dilation [27].

Polypectomy using electrocautery increases the risk of perforation through thermal injury to the colon wall. For this reason, the cold snare has been established to be safer when used for polyps less than $1 \mathrm{~cm}$ [28] and even larger than 1 $\mathrm{cm}$ in a recent study [29]. Cold snaring has also been reported to carry a lower bleeding risk in patients on anticoagulation or aspirin. Better control of the snare tip through practicing 
Table 2. Univariate Odds Ratio for Perforation Post-Colonoscopy in Teaching Facilities Compared to Non-Teaching by Logistic Regression Model

\begin{tabular}{|c|c|c|}
\hline Variables & Crude odds ratio with confidence interval & P value \\
\hline Perforation & $1.17(1.02-1.34)$ & 0.02 \\
\hline Age & $1.00(0.99-1)$ & 0.39 \\
\hline Ulcerative colitis & $2.67(1.67-4.28)$ & $<0.0001$ \\
\hline Crohn's disease & $2.71(1.9-3.85)$ & $<0.0001$ \\
\hline Race & $0.88(0.82-0.96)$ & 0.005 \\
\hline \multicolumn{3}{|l|}{ Insurance } \\
\hline Medicare & Referent & \\
\hline Medicaid & $0.81(0.62-1)$ & 0.12 \\
\hline 0 & Referent & \\
\hline $1-3$ & $0.72(0.54-0.96)$ & 0.027 \\
\hline$\geq 4$ & $0.69(0.52-0.90)$ & 0.008 \\
\hline
\end{tabular}

and changing angles is advised to decrease the perforation risk [28]. However, in our study, the removal of polyp did not yield any increase in the risk of perforation between the two study groups.

The highest risk of perforation in our study was in patients who underwent stricture dilation, followed by the presence of IBD. This may be related to the higher number of IBD, and stricture dilatation patients in teaching hospitals compared to non-teaching in our study.

Colonoscopy is essential in the care of patients with IBD. It is used to establish the diagnosis, grade the severity, assess response and screen for neoplasia [30]. IBD patients, and especially Crohn's disease, are known to develop stricture as a complication of their disease. Proposed explanations include

Table 3. Multivariate Odds Ratio for Perforation Post-Colonoscopy in Teaching Facilities Compared to Non-Teaching by Logistic Regression Model

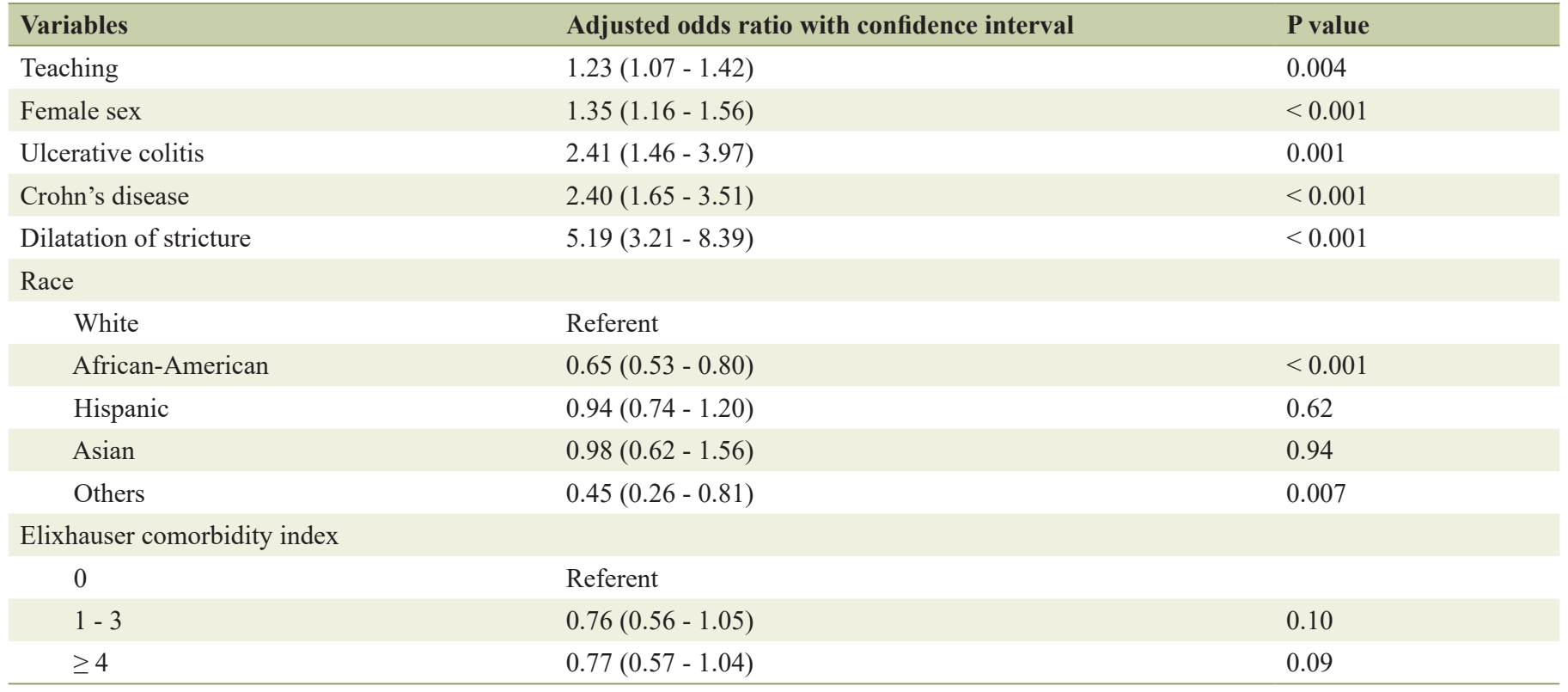


prolonged inflammation, hyperplasia of smooth muscles and hypertrophy of stem cells, all leading to a fibrosing reaction [31]. Previous studies reported an increased risk of perforation in IBD patients $[9,32]$. Possible mechanisms include excessive pressure from the air used in colonoscopy and direct injury from the scope [31]. Other risk factors include anatomical complications, including strictures, use of steroids and biological agents and history of abdominopelvic surgical interventions. Decreasing risk of pressure trauma and perforation may be achieved by using the minimum air insufflation and observing for abdominal distension, gradual dilation of IBD-related stricture and dilating to a maximum diameter of less than $25 \mathrm{~mm}[33,34]$.

Female gender is another risk factor for perforation in our study, agreeing with some previous studies [35]. Difficulty in colonoscopy in females may be associated with reduced abdomen cavity size, less resistance from lower abdomen muscle mass and increased depth of pelvis - all contributing to increased angulation and looping of the colon. Decreasing perforation risk may be achieved by frequent repositioning, applying pressure to the abdominal wall and the use of smaller size colonoscopes [36].

\section{Limitations}

Our study includes several limitations that should be mentioned. First, the data do not specify the severity of some variables like IBD or of the stricture, which may affect the outcome. Second, the data lack specific information about the involvement of fellows, and if so, the year of training for the fellows, as experience relates to complications risk as mentioned above. Third, no post-discharge follow-up data are included in the data set. Lastly, although the NIS database has been validated and vastly used across different specialties, errors related to variables in coding may occur.

\section{Conclusion}

Colonoscopy perforation rates were higher in teaching hospitals. Variables associated with increased risk were female gender, presence of IBD and dilation of strictures. More studies are needed to examine this association.

\section{Acknowledgments}

None to declare.

\section{Financial Disclosure}

None of the authors have any financial disclosures.

\section{Conflict of Interest}

All the authors have no conflict of interest to disclose.

\section{Informed Consent}

Formal consent is not needed for this type of study.

\section{Author Contributions}

Mowyad Khalid, Mazin Khalid and Vijay Gayam designed the research; Sandipan Chakraborty, Mohamed Abdallah and Zaid Kaloti did the literature review; Mazin Khalid, Osama Mukhtar and Omeralfaroug Adam performed the research and analyzed the data; Mowyad Khalid wrote the paper; Hammam Shereef, Ahmad Abu-Heija, Ahmed Yeddi and Stephanie Judd did the critical revision of manuscript for intellectual content.

\section{References}

1. Wolff WI. Colonoscopy: history and development. Am J Gastroenterol. 1989;84(9):1017-1025.

2. Ko CW, Dominitz JA. Complications of colonoscopy: magnitude and management. Gastrointest Endosc Clin N Am. 2010;20(4):659-671.

3. Rex DK, Schoenfeld PS, Cohen J, Pike IM, Adler DG, Fennerty MB, Lieb JG, 2nd, et al. Quality indicators for colonoscopy. Am J Gastroenterol. 2015;110(1):72-90.

4. Fishman LE. What types of hospitals form the safety net? Health Aff (Millwood). 1997;16(4):215-222.

5. Weissman JS, Gaskin DJ, Reuter J. Hospitals' care of uninsured patients during the 1990s: the relation of teaching status and managed care to changes in market share and market concentration. Inquiry. 2003;40(1):84-93.

6. Ayanian JZ, Weissman JS. Teaching hospitals and quality of care: a review of the literature. Milbank Q. 2002;80(3):569-593.

7. Mechanic R, Coleman K, Dobson A. Teaching hospital costs: implications for academic missions in a competitive market. JAMA. 1998;280(11):1015-1019.

8. Healthcare Cost and Utilization Project (HCUP) Database. Overview of the National (Nationwide) Inpatient Sample (NIS). Agency for Healthcare Research and Quality. 2018. https://www.hcup-us.ahrq.gov/nisoverview.jsp.

9. Navaneethan U, Parasa S, Venkatesh PG, Trikudanathan G, Shen B. Prevalence and risk factors for colonic perforation during colonoscopy in hospitalized inflammatory bowel disease patients. J Crohns Colitis. 2011;5(3):189195.

10. Desai R, Patel U, Goyal H. Does "July effect" exist in colonoscopies performed at teaching hospitals? Transl Gastroenterol Hepatol. 2018;3:28.

11. Farley DR, Bannon MP, Zietlow SP, Pemberton JH, Ilstrup DM, Larson DR. Management of colonoscopic perforations. Mayo Clin Proc. 1997;72(8):729-733.

12. Shahian DM, Liu X, Meyer GS, Normand SL. Comparing teaching versus nonteaching hospitals: the association of patient characteristics with teaching intensity for three common medical conditions. Acad Med. 2014;89(1):94106. 
13. Durairaj L, Will JG, Torner JC, Doebbeling BN. Prognostic factors for mortality following interhospital transfers to the medical intensive care unit of a tertiary referral center. Crit Care Med. 2003;31(7):1981-1986.

14. Seferian EG, Afessa B, Gajic O, Keegan MT, Hubmayr $\mathrm{RD}$, Mayo $\mathrm{E}$, Translational Research in Intensive $\mathrm{C}$. Comparison of community and referral intensive care unit patients in a tertiary medical center: evidence for referral bias in the critically ill. Crit Care Med. 2008;36(10):27792786.

15. Flabouris A, Hart GK, George C. Outcomes of patients admitted to tertiary intensive care units after interhospital transfer: comparison with patients admitted from emergency departments. Crit Care Resusc. 2008;10(2):97-105.

16. Dafnis G, Ekbom A, Pahlman L, Blomqvist P. Complications of diagnostic and therapeutic colonoscopy within a defined population in Sweden. Gastrointest Endosc. 2001;54(3):302-309.

17. Galandiuk $\mathrm{S}$, Ahmad $\mathrm{P}$. Impact of sedation and resident teaching on complications of colonoscopy. Dig Surg. 1998;15(1):60-63.

18. Viiala CH, Zimmerman M, Cullen DJ, Hoffman NE. Complication rates of colonoscopy in an Australian teaching hospital environment. Intern Med J. 2003;33(8):355-359.

19. Wexner SD, Garbus JE, Singh JJ, The SAGES Colonoscopy Outcomes Study Group. A prospective analysis of 13,580 colonoscopies. Reevaluation of credentialing guidelines. Surg Endosc. 2001;15(3):251-261.

20. Anderson ML, Pasha TM, Leighton JA. Endoscopic perforation of the colon: lessons from a 10-year study. Am J Gastroenterol. 2000;95(12):3418-3422.

21. Rogers BH, Silvis SE, Nebel OT, Sugawa C, Mandelstam P. Complications of flexible fiberoptic colonoscopy and polypectomy. Gastrointest Endosc. 1975;22(2):73-77.

22. Fruhmorgen P, Demling L. Complications of diagnostic and therapeutic colonoscopy in the Federal Republic of Germany. Results of an inquiry. Endoscopy. 1979;11(2):146-150.

23. Marshall JB. Technical proficiency of trainees performing colonoscopy: a learning curve. Gastrointest Endosc. 1995;42(4):287-291.

24. Brynitz S, Kjaergard H, Struckmann J. Perforations from colonoscopy during diagnosis and treatment of polyps. Ann Chir Gynaecol. 1986;75(3):142-145.
25. Fujishiro M, Yahagi N, Kakushima N, Kodashima S, Muraki Y, Ono S, Yamamichi N, et al. Outcomes of endoscopic submucosal dissection for colorectal epithelial neoplasms in 200 consecutive cases. Clin Gastroenterol Hepatol. 2007;5(6):678-683; quiz 645.

26. Perez Roldan F, Gonzalez Carro P, Legaz Huidobro ML, Villafanez Garcia MC, Soto Fernandez S, de Pedro Esteban A, Roncero Garcia-Escribano O, et al. Endoscopic resection of large colorectal polyps. Rev Esp Enferm Dig. 2004;96(1):36-47.

27. Nomura E, Takagi S, Kikuchi T, Negoro K, Takahashi S, Kinouchi Y, Hiwatashi N, et al. Efficacy and safety of endoscopic balloon dilation for Crohn's strictures. Dis Colon Rectum. 2006;49(10 Suppl):S59-67.

28. Hewett DG. Colonoscopic polypectomy: current techniques and controversies. Gastroenterol Clin North Am. 2013;42(3):443-458.

29. Piraka C, Saeed A, Waljee AK, Pillai A, Stidham R, Elmunzer BJ. Cold snare polypectomy for non-pedunculated colon polyps greater than $1 \mathrm{~cm}$. Endosc Int Open. 2017;5(3):E184-E189.

30. Shergill AK, et al. The role of endoscopy in inflammatory bowel disease. Gastrointest Endosc. 2015;81(5):11011121.e1-13.

31. Makkar R, Bo S. Colonoscopic perforation in inflammatory bowel disease. Gastroenterol Hepatol (N Y). 2013;9(9):573-583.

32. Arora G, Mannalithara A, Singh G, Gerson LB, Triadafilopoulos G. Risk of perforation from a colonoscopy in adults: a large population-based study. Gastrointest Endosc. 2009;69(3 Pt 2):654-664.

33. Hirai F. Current status of endoscopic balloon dilation for Crohn's disease. Intest Res. 2017;15(2):166-173.

34. Polter DE. Risk of colon perforation during colonoscopy at Baylor University Medical Center. Proc (Bayl Univ Med Cent). 2015;28(1):3-6.

35. Korman LY, Overholt BF, Box T, Winker CK. Perforation during colonoscopy in endoscopic ambulatory surgical centers. Gastrointest Endosc. 2003;58(4):554-557.

36. Kashiwagi K, Inoue N, Yoshida T, Bessho R, Yoneno K, Imaeda $\mathrm{H}$, Ogata $\mathrm{H}$, et al. The impact of visceral adipose tissue as best predictor for difficult colonoscopy and the clinical utility of a long small-caliber scope as rescue. PLoS One. 2017;12(12):e0189817. 